\title{
Kinetics of plasma von Willebrand factor in acute myocardial infarction patients: a meta-analysis
}

\author{
Xia Wang ${ }^{1}$, Junyu Zhao ${ }^{2}$, Yong Zhang ${ }^{3}$, Xiujuan $\mathrm{Xue}^{4}$, Jie Yin ${ }^{3}$, Lin Liao ${ }^{2}$, Cuiping $\mathrm{Xu}^{4}$, \\ Yinglong Hou ${ }^{3}$, Suhua Yan ${ }^{3}$ and Ju Liu ${ }^{1}$ \\ ${ }^{1}$ Medical Research Center, Shandong Provincial Qianfoshan Hospital, Shandong University, Jinan, 250014 Shandong, China \\ ${ }^{2}$ Department of Endocrinology, Shandong Provincial Qianfoshan Hospital, Shandong University, Jinan, 250014 Shandong, China \\ ${ }^{3}$ Department of Cardiology, Shandong Provincial Qianfoshan Hospital, Shandong University, Jinan, 250014 Shandong, China \\ ${ }^{4}$ Department of Nursing, Shandong Provincial Qianfoshan Hospital, Shandong University, Jinan, 250014 Shandong, China
}

Correspondence to: Ju Liu, email: ju.liu@sdu.edu.cn

Keywords: von Willebrand factor, kinetics, acute myocardial infarction, meta-analysis

Received: May 16, 2017 Accepted: July 26, $2017 \quad$ Published: August 09, 2017

Copyright: Wang et al. This is an open-access article distributed under the terms of the Creative Commons Attribution License 3.0 (CC BY $3.0)$, which permits unrestricted use, distribution, and reproduction in any medium, provided the original author and source are credited.

\section{ABSTRACT}

Previous studies have shown a variation in plasma level of von Willebrand factor (vWF) in acute myocardial infarction (AMI) patients but with contentious results. In this study, we performed a meta-analysis to evaluate the kinetics of plasma vWF after AMI. A total of $\mathbf{1 1}$ qualified studies were obtained through systematical search in PubMed, Web of science, Cochrane Library database and CNKI, followed by search of reference lists, involving 519 AMI patients and 466 non-AMI controls. The standard mean difference (SMD) and 95\% confidence intervals (95\% CI) were calculated using random-effects model. Results indicated that the plasma vWF was significantly increased in the first several hours after onset of AMI (SMD $=1.94,95 \%$ CI $=1.39-$ $2.48, P<0.001)$ and stayed at high level until $24 \mathrm{~h}(\mathrm{SMD}=1.17,95 \% \mathrm{CI}=0.45-1.89$, $P=0.001)$. Elevated level of vWF appeared to persist for one week and reduced to normal until the fourteenth day after AMI (SMD $=0.44,95 \%$ CI $=-0.14-1.02$, $P=0.14)$. Subgroup analysis revealed that the high level of vWF lasted just for 1 day in patients with a symptom duration $\leq 6 \mathrm{~h}$ before admission. For patients with a symptom duration $>6 \mathrm{~h}$, elevated vWF was found in all 7 days except day 1. Our findings determined the kinetics of plasma vWF after AMI, and might provide a new insight in monitoring AMI progression.

\section{INTRODUCTION}

Acute myocardial infarction (AMI) is one of leading causes of mortality. In 2008, over 3,000,000 individuals developed ST-elevated myocardial infarction (SETMI) and 4,000,000 developed non-ST-elevated myocardial infarction (non-STEMI) worldwide [1]. AMI is caused by rupture of atherosclerotic plaques, exposure of sub-endothelial procoagulant factors, and subsequent thrombus formation, which leads to the complete or incomplete occlusion of coronary arteries [2]. As the most serious type of acute coronary syndromes (ACS), AMI may lead to cardiac death and/or heart failure [3]. The current diagnosis for AMI is mainly dependent on electrocardiograph (ECG) and circulating myocardial enzymes such as ultrasensitive troponin I or $\mathrm{T}$ and creatine kinase MB [4]. To date, no clinical marker is available for the accurate assessment of AMI process [5].

Von Willebrand factor (vWF), a large multimeric plasma glycoprotein, is well known for its role in hemostasis, where it binds to platelets and to the constituents of the sub-endothelial connective tissue $[6,7]$. Following synthesis, vWF is transported to storage organelles in both megakaryocytes/platelets ( $\alpha$-granules) and endothelial cells (Weibel-Palade bodies) [8, 9]. Although platelets secrete vWF, circulating vWF level has been shown to depend almost entirely on vWF from endothelial cells $[6,10]$ through both consecutive and regulated pathways. A large amount of vWF is stored in Weibel-Palade bodies in endothelial cells and released 
towards the lumen of blood vessels in response to various stimuli [11, 12]. Particularly, vWF is released during endothelial injury and is recognized as a marker of endothelial dysfunction $[13,14]$.

Previous studies have suggested a crucial role of vWF in thrombus formation at sites of high shear rates by mediating platelets adhesion and aggregation [15-17]. Increased plasma vWF level is considered as one of the risk factors for AMI [18-20]. Furthermore, an elevation in plasma level of $\mathrm{VWF}$ has been extensively reported in AMI patients [21-32], but the dynamic changes of $\mathrm{vWF}$ concentration during the progression of AMI have been contentious as they can be influenced by many factors. For example, patients with Thrombolysis in Myocardial Infarction (TIMI) grade 3 were reported to have less vWF in plasma than that of other patients [24, 30]. To get a more comprehensive understanding of variations of the vWF levels in AMI patients, we performed a metaanalysis, including 519 AMI patients and 466 healthy or non-ACS controls, to determine the kinetics of plasma vWF after AMI.

\section{RESULTS}

\section{Search results and characteristics of included studies}

The initial search strategy yielded 627 hits, of which 80 were excluded for duplicated recordings. After carefully reviewing the titles and abstracts, 41 candidate articles were screened out for further full-text reading, and 506 unrelated articles were excluded. In addition, 30 full-text reviewed articles were excluded due to disqualification of inclusion criteria. The flow chart of the entire literature search process is shown in Figure 1. The study of Xie et al. [26] was eliminated due to the low quality (5 scores). Patients in study of Zhou et al. [24] were classified into two groups according to TIMI grade after reperfusion therapy, and these two groups were independently incorporated in our meta-analysis. As a result, we included 11eligible studies [22-25, 27-32] in this meta- analysis with a total of 519 AMI patients and 466 healthy or non-ACS controls. The included studies provided the plasma level of vWF at different time points after AMI (from on admission to 14 days). The control group included healthy volunteers and patients with a normal coronary angiography. The characteristics of the 11 eligible articles are summarized in Table 1.

\section{Kinetics of plasma vWF}

The meta-analysis revealed that plasma level of vWF was significantly higher in AMI patients compared with healthy volunteers or non-ACS patients. The high level of plasma vWF persisted for one week. The pooled SMD was $1.94(95 \% \mathrm{CI}=1.39-2.48, P<0.001)$ on admission, $1.17(95 \% \mathrm{CI}=0.45-1.89, P=0.001)$ and $1.28(95 \% \mathrm{CI}=0.11-2.45, P=0.03)$ on day 1 and day

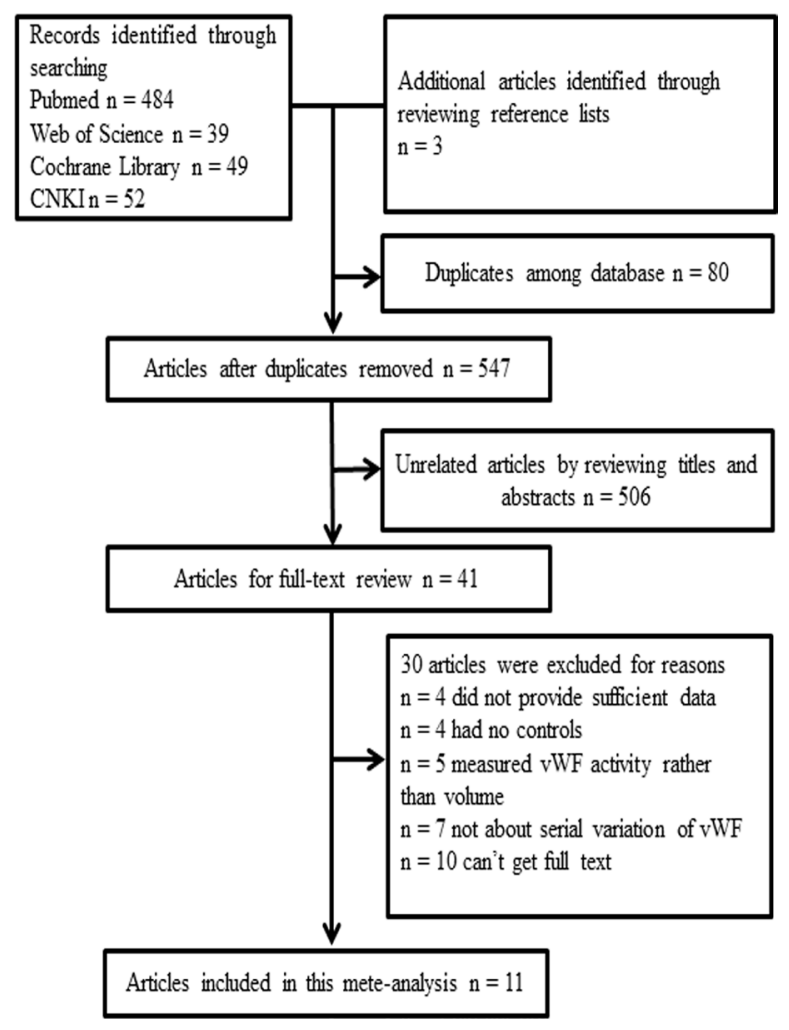

Figure 1: The flow chart of the literature search and selection process. 
Table 1: Characteristics of the studies included in the meta-analysis

\begin{tabular}{|c|c|c|c|c|c|c|c|c|}
\hline Year & Author & $\begin{array}{l}\text { Age (mean) } \\
\text { C/CTL }\end{array}$ & $\begin{array}{l}\text { Gender (male \%) } \\
\text { C/CTL }\end{array}$ & $\begin{array}{l}\text { Sample size } \\
\text { C/CTL }\end{array}$ & $\begin{array}{l}\text { Duration } \\
\text { before } \\
\text { admission }\end{array}$ & $\begin{array}{l}\text { Treatment } \\
\text { modality }\end{array}$ & $\begin{array}{l}\text { Measuring } \\
\text { methods }\end{array}$ & $\begin{array}{l}\text { TIMI grade } \\
\text { (number) }\end{array}$ \\
\hline 2016 & Teunissen [22] & $59 / 59$ & $78 / 78$ & $30 / 30$ & $\leqq 6 \mathrm{~h}$ & $\begin{array}{l}\text { PCI \& antiplatelet \& } \\
\text { anticoagulation }\end{array}$ & ELISA & $\begin{array}{l}3(57) \\
2(3)\end{array}$ \\
\hline 2015 & Regueiro [32] & $53.7 / 54.7$ & $85 / 84.7$ & $100 / 98$ & $\leqq 24 \mathrm{~h}$ & PCI or Thrombolysis & ELISA & NR \\
\hline 2012 & Jia [23] & $62.64 / 47.45$ & $73 / 68$ & $48 / 19$ & NR & $\begin{array}{l}\text { Antiplatelet \& } \\
\text { anticoagulation }\end{array}$ & ELISA & NR \\
\hline 2011(1) & Zhou [24] & $63.4 / 58.44$ & $58 / 60$ & $43 / 22$ & NR & PCI & ELISA & $3(43)$ \\
\hline 2011(2) & Zhou [24] & $63.4 / 58.44$ & $60 / 60$ & $43 / 21$ & NR & PCI & ELISA & $\leqq 2(43)$ \\
\hline 2007 & Matsukawa [25] & $65 / 65$ & $73 / 63$ & $92 / 40$ & $\leqq 24 \mathrm{~h}$ & PCI \& antiplatelet & ELISA & NR \\
\hline 2000 & Sakai [27] & $59 / 50$ & NR & $51 / 58$ & $\leqq 6 \mathrm{~h}$ & $\begin{array}{l}\text { PCI \& antiplatelet \& } \\
\text { anticoagulation }\end{array}$ & EIA & NR \\
\hline 2000 & Lip [31] & $62 / 62$ & $70 / 70$ & $17 / 59$ & $\leqq 12 \mathrm{~h}$ & $\begin{array}{l}\text { Thrombolysis \& } \\
\text { anticoagulation }\end{array}$ & ELISA & NR \\
\hline 2000 & Xie [26] & $68 / 61$ & $75 / 50$ & $16 / 16$ & NR & PCI or Thrombolysis & EIA & $3(16)$ \\
\hline 1996 & Tousoulis [28] & $60 / 46$ & $94 / 38$ & $16 / 8$ & NR & $\begin{array}{l}\text { Antiplatelet \& } \\
\text { anticoagulation }\end{array}$ & ELISA & NR \\
\hline 1992 & Norris [29] & $58 / 52$ & $81 / 81$ & $51 / 36$ & $\leqq 6 \mathrm{~h}$ & Thrombolysis & EIA & NR \\
\hline 1990 & Andreotti [30] & $58 / 58$ & $71 / 71$ & $12 / 12$ & $\leqq 6 \mathrm{~h}$ & $\begin{array}{l}\text { Thrombolysis \& } \\
\text { anticoagulation }\end{array}$ & ELISA & $\begin{array}{l}\geqq 2(16) \\
<2(8)\end{array}$ \\
\hline
\end{tabular}

Abbreviations: C/CTL, case/control group; NR, unreported; PCI, percutaneous coronary intervention; ELISA, enzyme-linked immunosorbent assay; EIA, enzyme immunoassay; TIMI, thrombolysis in myocardial infarction.

$2,0.81(95 \% \mathrm{CI}=0.29-1.34, P=0.002)$ on day $3-4$, and $1.02(95 \% \mathrm{CI}=0.54-1.50, P<0.001)$ on day 7 . However, no statistically significant difference was found on day $14(\mathrm{SMD}=0.44,95 \% \mathrm{CI}=-0.14-1.02, P=0.14)$. It was noted that there was significant heterogeneity across studies (Figure 2). As a result, random-effects model was adapted.

\section{Quality evaluation}

The results of the quality assessment of the included studies are shown in Table 2. Eight studies were determined as high quality [22, 24, 25, 27, 29-32], and two were determined as medium quality $[23,28]$. These 11 studies received an average score of 7.18. One report [26] of low quality ( 5 scores) was excluded from this metaanalysis.

\section{Subgroup analysis}

Subgroup analyses were conducted in all the groups except the groups of day 2 and 14 after AMI since no sufficient studies was included for these two groups. Results showed that for the AMI patients with a symptom duration $\leqq 6 \mathrm{~h}$ before admission, significantly elevated level of plasma vWF was identified on admission and on day 1 after AMI $(\mathrm{SMD}=1.19,95 \% \mathrm{CI}=0.90-1.48$, $P<0.001$ on admission; $\mathrm{SMD}=1.21,95 \% \mathrm{CI}=0.11-$ $2.31, P=0.03$ on day 1 ), while no significant elevation was found on 3-4 days and 7 days from AMI (SMD =
$0.93,95 \% \mathrm{CI}=-0.10-1.97, P=0.08$ on day $3-4$; SMD $=0.94,95 \% \mathrm{CI}=-0.22-2.10, P=0.11$ on day 7 ). For patients with a symptom duration $>6 \mathrm{~h}$ or unreported, elevated vWF was found in all 7 days except day 1 (Table 3 ). In patients treated with percutaneous coronary intervention (PCI), the higher level of vWF persisted for 7 days. However, for those without PCI, significant difference was found only on day 1 while disappeared on day 3 and 4 after therapy. On day 7, the pooled SMD was $0.49(95 \% \mathrm{CI}=0.12-0.85, P=0.009)$ for patients with TIMI grade 3 and $1.29(95 \% \mathrm{CI}=0.73-1.84, P<0.001)$ for the others, suggesting a higher level of vWF was found even under an ideal reflow condition of coronary.

\section{Sensitivity analysis}

Each study was excluded sequentially to evaluate the influence of an individual study on the results. No study fundamentally changed the combined effects at any time points except on day 14. Furthermore, the studies of Sakai et al. [27] and Jia et al. [23] were found to be the main source of heterogeneity. Elimination of the former study yielded similar results without heterogeneity (on day 2: $\mathrm{SMD}=0.69,95 \% \mathrm{CI}=0.09-1.29, P=0.02$, $I^{2}=0 \%$; on day 3-4: $\mathrm{SMD}=0.55,95 \% \mathrm{CI}=0.28-0.83$, $\left.P<0.001, I^{2}=0 \%\right)$. When the later study was eliminated from analysis, a statistically significant difference of plasma vWF was also found on day $14(\mathrm{SMD}=0.69,95 \%$ $\mathrm{CI}=0.36-1.02, P<0.001, I^{2}=0 \%$ ), suggesting that the original result for 14 days after AMI was not stable. 


\section{Publication bias}

Funnel plot was performed to evaluate the publication bias of literatures. As shown in Figure 3, no significant publication bias was observed.

\section{DISCUSSION}

Over the 11 studies, 519 AMI patients and 466 healthy or non-ACS controls were included in this metaanalysis. The pooled SMD indicated that the concentration of plasma vWF was significantly higher in AMI patients than controls and persisted for one week after reperfusion therapy. Sensitivity analysis showed that the pooled results were robust. However the result for 14 days after AMI was not stable because a reverse change of the pooled SMD was caused by the removal of Jia et al. literature. Thus, additional studies are needed to obtain a more reliable assessment of plasma vWF level 14 days after AMI. In addition, for patients with a symptom duration $>6 \mathrm{~h}$ or unreported, significantly elevated vWF was found in all 7 days except day 1 . The negative result of day 1 may be resulted from unrevealed clinical heterogeneity due to the limited information provided by certain literatures.

$\mathrm{vWF}$ is a multimeric protein primarily produced by endothelial cells in circulation [6]. Newly released vWF composes a relatively higher amount of larger multimers which have a crucial role in platelet thrombus formation [33]. After release, the peptide bond within the vWF A2 domain is cleaved by ADAMTS13 which maintains the normal size distribution of vWF multimers [34-36]. Decreased ADAMTS13 and increased vWF multimers were found in AMI patients [22, 25, 26, 37, 38], suggesting that these factors could be biomarkers of AMI progression. vWF secretion can be stimulated by inflammatory cytokines [39] and hypoxia [40]. Our subgroup analysis revealed that symptom duration before admission and TIMI grade after reperfusion therapy also had various effects on vWF level after the onset of AMI. Results indicated that early on admission could prevent further elevation of vWF level. However, PCI, one of the most common surgical procedures for myocardial infarction patients, did not show a significant impact on plasma vWF in AMI patients.

vWF plays a pivotal role in the process of thrombus formation, especially under flow conditions [41]. First, vWF promotes platelet aggregation by binding to the receptors GPIb-IX-V complex and GPIIb/IIIa on the surface of platelet [42]. Second, vWF mediates platelet adhesion through binding to collagens located in the subendothelial connective tissue [43]. Furthermore, $\mathrm{vWF}$ acts as a carrier protein for coagulation factor

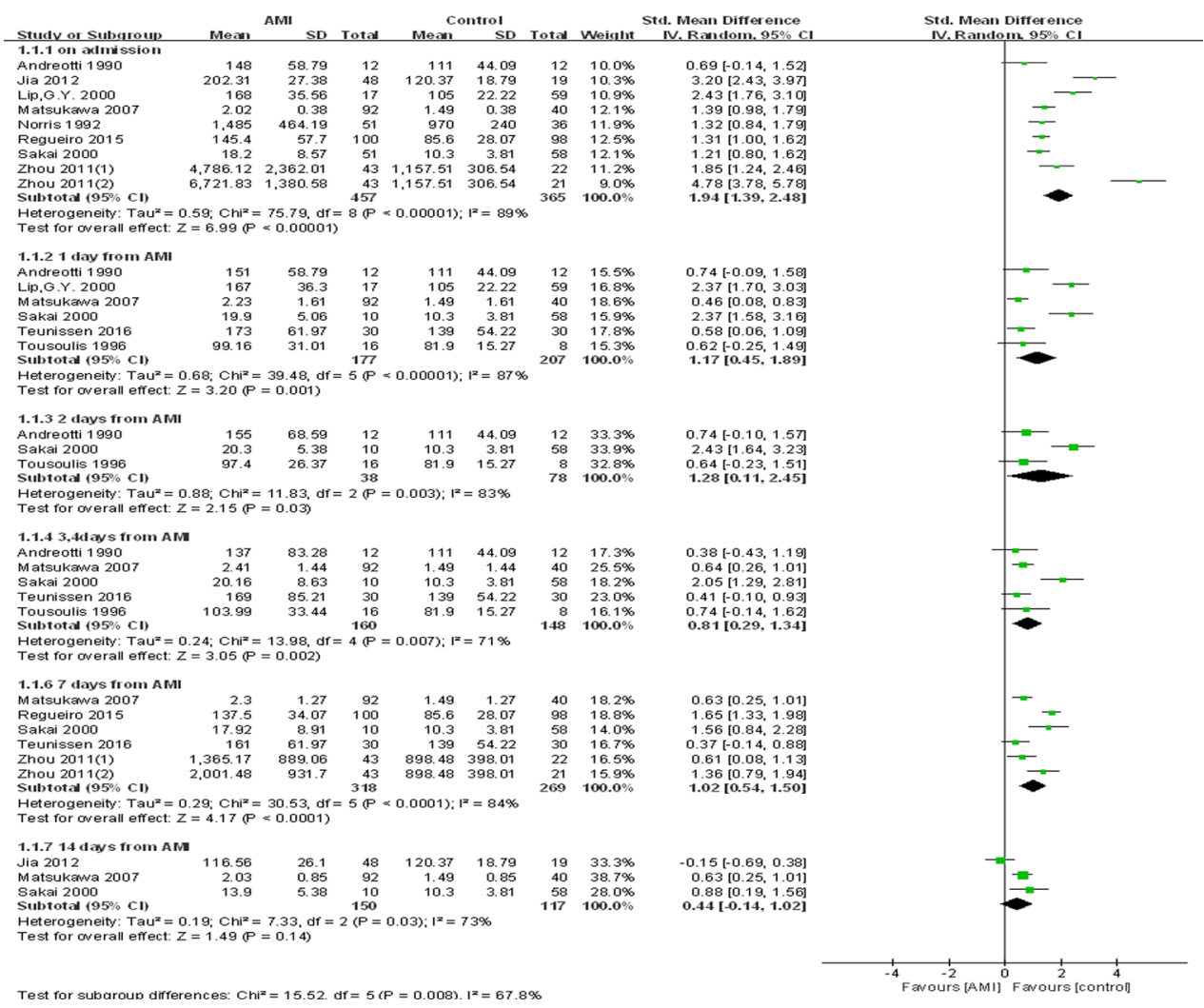

Figure 2: Forest plot of meta-analysis of kinetics in plasma vWF concentration after AMI. Each block represents a study and the area of each block is proportional to the weight of that study. The horizontal line represents each study's $95 \%$ confidence interval (CI) for the effect. The centre of the diamond is the pooled effect across studies, and the width of the diamond denotes its $95 \%$ CI. AMI, acute myocardial infarction; IV, invers variance; SD, standard deviation; Std, standard. 
Table 2: Quality assessment of the included studies based on the Newcastle-Ottawa Scale

\begin{tabular}{llllll}
\hline Author & Study design & Selection & Comparability & Outcome & Total scores \\
\hline Teunissen [22] & Cohort study & $\star \star \star$ & $\star \star$ & $\star \star \star$ & 8 \\
Regueiro [32] & Cohort study & $\star \star \star$ & $\star \star$ & $\star \star \star$ & 8 \\
Jia [23] & Cohort study & $\star \star$ & $\star$ & $\star \star \star$ & 6 \\
Zhou [24] & Cohort study & $\star \star \star$ & $\star \star$ & $\star \star \star$ & 8 \\
Matsukawa [25] & Cohort study & $\star \star \star$ & $\star \star$ & $\star \star \star$ & 8 \\
Sakai [27] & Cohort study & $\star \star \star$ & $\star \star$ & $\star \star$ & 7 \\
Lip [31] & Cohort study & $\star \star \star$ & $\star \star$ & $\star \star \star$ & 8 \\
Xie [26] & Cohort study & $\star$ & $\star$ & $\star \star \star$ & 5 \\
Tousoulis [28] & Cohort study & $\star \star$ & $\star$ & $\star \star \star$ & 6 \\
Norris [29] & Cohort study & $\star \star$ & $\star \star$ & $\star \star \star$ & 7 \\
Andreotti [30] & Cohort study & $\star \star \star$ & $\star \star$ & $\star \star \star$ & 8 \\
\hline
\end{tabular}

VIII and facilitates fibrin clot formation [2]. AMI is a process involving the formation of thrombus, the injury of endothelial cells and the exposure of subendothelial collagen. Previous studies have found an association between vWF and AMI [22-32]. The protocol for detection of plasma vWF level has been well-established in clinical laboratories. Compared with existing myocardial enzymology, vWF has advantages as an indicator of AMI progression. Myoglobin is a sensitive but not specific biomarker of myocardial injury, as it appears in blood 1-3 $\mathrm{h}$ after AMI and returns to normal values after $1-1.5$ days $[44,45]$. CK-MB mass is only sensitive in 6-72 hours after the onset of AMI [46]. At present, cardiac troponins are well accepted biomarkers for diagnosing myocardial injury for its rapid release and sufficient diagnostic window [47]. Similarly, the plasma vWF elevates rapidly after the onset of AMI and persists at a high level for at least one week after AMI. Although
A

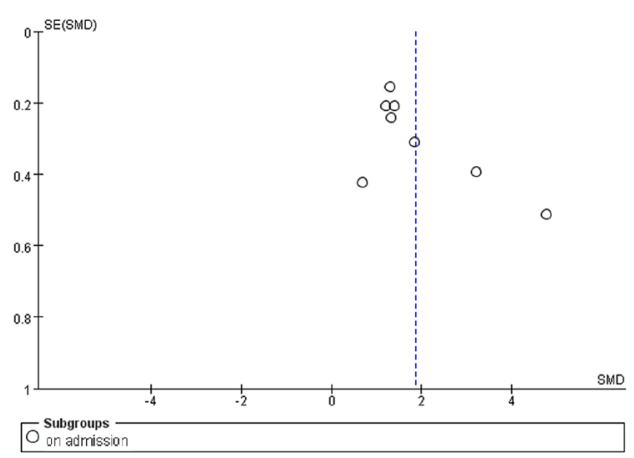

C



B



D

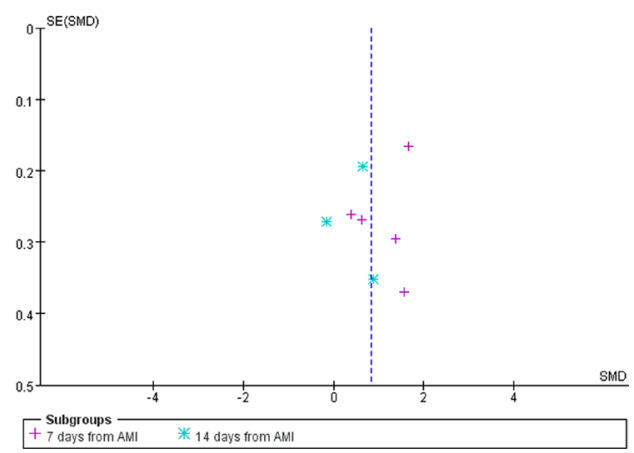

Figure 3: Funnel plot of publication bias. No publication bias was pbserved in any groups. (A) Funnel plot of studies on admission. (B) Funnel plot of studies on day 1 and 2 after AMI. (C) Funnel plot of studies on day 3 and 4 after AMI. (D) Funnel plot of studies on day 7 and 14 after AMI. 
Table 3: Summary results of plasma vWF levels in AMI patients and controls

\begin{tabular}{|c|c|c|c|c|c|c|c|c|c|c|c|}
\hline \multirow{2}{*}{\multicolumn{2}{|c|}{ Variables }} & \multirow{2}{*}{$\begin{array}{c}\text { No. of } \\
\text { comparisons }\end{array}$} & \multicolumn{2}{|c|}{ No. of subjects } & \multicolumn{3}{|c|}{ Meta-analysis } & \multicolumn{2}{|c|}{ Heterogeneity } & \multicolumn{2}{|c|}{$\begin{array}{l}\text { Test for subgroup } \\
\text { differences }\end{array}$} \\
\hline & & & AMI & Controls & SMD & $95 \% \mathrm{CI}$ & $P$ & $I^{2}(\%)$ & $P$ & $I^{2}(\%)$ & $P$ \\
\hline \multicolumn{12}{|c|}{ Duration before admission } \\
\hline \multirow[t]{2}{*}{ On admission } & $\leqq 6 \mathrm{~h}$ & 3 & 114 & 106 & 1.19 & $0.90-1.48$ & $<0.001$ & 0 & 0.43 & 87.4 & 0.005 \\
\hline & $>6 \mathrm{~h} / \mathrm{NR}$ & 6 & 343 & 259 & 2.40 & $1.61-3.20$ & $<0.001$ & 92 & $<0.001$ & & \\
\hline \multirow[t]{2}{*}{1 day } & $\leqq 6 \mathrm{~h}$ & 3 & 52 & 100 & 1.21 & $0.11-2.31$ & 0.03 & 86 & $<0.001$ & 0 & 0.94 \\
\hline & $>6 \mathrm{~h} / \mathrm{NR}$ & 3 & 125 & 107 & 1.14 & $-0.10-2.39$ & 0.07 & 92 & $<0.001$ & & \\
\hline \multirow[t]{2}{*}{ 3-4 days } & $\leqq 6 \mathrm{~h}$ & 3 & 52 & 100 & 0.93 & $-0.10-1.97$ & 0.08 & 85 & 0.001 & 0 & 0.47 \\
\hline & $>6 \mathrm{~h} / \mathrm{NR}$ & 2 & 108 & 48 & 0.65 & $0.30-1.00$ & $<0.001$ & 0 & 0.55 & & \\
\hline \multirow[t]{2}{*}{7 days } & $\leqq 6 \mathrm{~h}$ & 2 & 40 & 88 & 0.94 & $-0.22-2.10$ & 0.11 & 85 & 0.009 & 0 & 0.93 \\
\hline & $>6 \mathrm{~h} / \mathrm{NR}$ & 4 & 278 & 181 & 1.07 & $0.49-1.65$ & 0.0003 & 86 & $<0.001$ & & \\
\hline \multicolumn{12}{|l|}{ PCI } \\
\hline \multirow[t]{2}{*}{1 day } & Yes & 3 & 132 & 128 & 1.07 & $0.12-2.03$ & 0.03 & 90 & $<0.001$ & 0 & 0.80 \\
\hline & No & 3 & 45 & 79 & 1.27 & $0.08-2.45$ & 0.04 & 85 & 0.001 & & \\
\hline \multirow[t]{2}{*}{ 3-4 days } & Yes & 3 & 132 & 128 & 0.97 & $0.18-1.76$ & 0.02 & 85 & 0.001 & 0 & 0.39 \\
\hline & No & 2 & 28 & 20 & 0.54 & $-0.05-1.14$ & 0.07 & 0 & 0.55 & & \\
\hline \multicolumn{12}{|l|}{ TIMI grade } \\
\hline \multirow[t]{2}{*}{7 days } & $\mathrm{TIMI}=3$ & 2 & 73 & 52 & 0.49 & $0.12-0.85$ & 0.009 & 0 & 0.53 & 82.1 & 0.02 \\
\hline & $\mathrm{TIMI} \leqq 2 / \mathrm{NR}$ & 4 & 245 & 217 & 1.29 & $0.73-1.84$ & $<0.001$ & 82 & $<0.001$ & & \\
\hline
\end{tabular}

Abbreviations: No, number; AMI, acute myocardial infarction; SMD, standardized mean difference; NR, unreported; PCI, percutaneous coronary intervention; TIMI, thrombolysis in myocardial infarction.

whether vWF plays a causal role in AMI remains unclear, the increase of vWF has prognostic value and might be used as an independent predictor for short-term adverse clinical outcomes [18, 48-50].

Our study has several advantages. First, this study meta-analytically identified the dynamic changes of plasma vWF in AMI patients and its influencing factors. The dramatic increase of plasma vWF implies its potential roles in the early diagnosis of AMI, and its kinetics in plasma levels could serve as an adjunct to the detection of AMI progression. Second, all the studies included in this meta-analysis were medium-to-high quality as assessed by Newcastle-Ottawa Quality Assessment Scale. Third, both sensitivity analysis and publication bias assessment confirmed the robustness and reliability of our results.

However, there were limitations in our study. First, significant heterogeneity was found in this meta-analysis. When the publication leading to major heterogeneity was eliminated, the difference of plasma vWF level was significant at 14 days after AMI, which was opposite to the original result. Second, detailed information regarding symptom duration before admission and TIMI grade were not available in several studies, which were important considerations for subgroup analysis. Moreover, we were unable to determine a causal or consequential role of vWF in progression of AMI.

In conclusion, our meta-analysis confirmed that plasma level of vWF is remarkably elevated in AMI patients compared with healthy or non-ACS controls. The higher level of plasma vWF persists at least for one week, and then gradually reduces to normal levels. This study suggests that the detection of plasma vWF levels may be useful in clinical evaluation of AMI. However, the conclusions should be interpreted with caution due to the limited sample size. Further studies are needed to achieve more comprehensive assessment of kinetics of plasma vWF after AMI.

\section{MATERIALS AND METHODS}

\section{Search strategy}

A systematic review of the literature was performed in PubMed, Web of Science, Cochrane Library database and CNKI online facilities. Studies reporting the variation of plasma vWF in AMI patients and published up to August 2016 were identified and analyzed, with a language restriction of English and Chinese. Both Medical Subject Heading (MeSH) terms and free text terms were used. For example, the search terms for vWF were "von Willebrand Factor", "Factor VIIIR-Ag", "Factor VIIIR-RCo", "Ristocetin-Willebrand Factor", "von Willebrand Protein", "Factor VIII-Related Antigen", "Ristocetin Cofactor", "Plasma Factor VIII Complex" and "vWF". The search terms for AMI were "Myocardial Infarction", "Infarct*, Myocardial", "Myocardial Infarct*", "Cardiovascular 
Stroke*", "Stroke*, Cardiovascular", "Heart Attack*" and "AMI". In addition, relevant reviews and articles on the citation lists were manually searched to identify other potentially eligible studies.

\section{Study selection and data extraction}

Two reviewers independently screened the titles, abstracts, and full texts of selected articles. The inclusion criteria included: (1) studies reporting the dynamic changes of plasma vWF after AMI; (2) specified diagnosis of AMI according to both clinical syndromes and ECG or myocardial enzymes tests; (3) studies written in English or Chinese. Exclusion criteria were settled as follows: (1) studies that were not related to the variation of vWF after AMI; (2) studies conducted on patients who had other severe disease such as von willebrand disease, or that were not on humans; (3) studies lacking complete data or without controls.

The following data were extracted from each eligible study if available: first author's name, publication year, age and sample size, percentage of males, mean and standard deviation (mean $\pm \mathrm{SD}$ ) or mean and standard error (mean $\pm \mathrm{SE}$ ) of plasma $\mathrm{vWF}$ concentration, treatment modality, symptom duration before admission, TIMI grade and measuring methods. In two studies where the data were presented in graph format but authors could not be reached, we extracted the data using Engauge Digitizer software (version4.1, free software downloaded from http://sourceforge.net). Furthermore, if the data were presented in median and interquartile range (IQR) format, SMD was calculated according to the formulations recommended by Cochrane Handbooks. All the information was collected by two independent reviewers and any discrepancy was resolved by discussion with each other or by a third author.

\section{Quality assessment}

The methodological quality of the included studies was assessed by two independent authors according to the criteria of Newcastle-Ottawa Quality Assessment scale (NOS) for assessing the quality of nonrandomized and observational studies in meta-analysis. Those scored $\geqq 7$ were considered as high quality and those scored $\leqq 5$ as low quality.

\section{Statistical analysis}

All the statistical analyses were performed using Review Manager software (RevMan5.3, Cochrane Collaboration, Oxford, UK, http://community.cochrane. org). We calculated SMD with $95 \%$ CI as a measure of pooled effects because different units of measurement were used across studies ( $\%, \mathrm{ng} / \mathrm{ml}, \mathrm{ug} / \mathrm{ml}, \mathrm{U} / \mathrm{L}, \mathrm{U} / \mathrm{ml}, \mathrm{IU} / \mathrm{L})$. A $P$ value $<0.05$ was considered statistically significant. All the studies were weighted by an inverse-variance method, thus the studies with larger samples accounted for higher weight. Random-effects model was chosen considering that there were potential heterogeneity across studies resulted from the variability in ethnicity and race of the subjects, differences in disease severity, inconsistent control of confounding factors and other unavailable information. Inter-study heterogeneity was evaluated using the Cochran's Q and Higgins's $I^{2}$ statistics, and a significant heterogeneity was considered if $P<0.1$ or $I^{2}>50 \%$.

Subsequent subgroup analyses were conducted to identify the source of potential heterogeneity based on the symptom duration before admission ( $\leqq 6 \mathrm{~h}$ or longer), treatment modality (PCI or thrombolysis), and TIMI grades (TIMI $=3$ or not) after reperfusion therapy. We also performed sensitivity analysis by removing studies one by one to estimate the stability of meta-analysis. In addition, publication bias for each group studies was assessed by visual inspection of funnel plot.

\section{Abbreviations}

vWF: von Willebrand factor; AMI: acute myocardial infarction; SMD: standard mean difference; 95\% CI: 95\% confidence intervals;STMI: ST-elevated myocardial infarction; non-STEMI: non-ST-elevated myocardial infarction; ACS: acute coronary syndromes; ECG: electrocardiograph; TIMI: Thrombolysis in Myocardial Infarction; PCI: percutaneous coronary intervention; SD: standard deviation; SE: standard error; IQR: interquartile range; NOS: Newcastle-Ottawa Quality Assessment Scale;CK-MB: creatine kinase MB.

\section{Author contributions}

$\mathrm{JL}$ and $\mathrm{XW}$ designed the study and wrote the manuscript. XW, YZ, JZ, XX and JY performed the literature searches and collected the data. XW, CX, LL, YH, HY and JL performed the statistical analysis. All authors approved the final manuscript.

\section{CONFLICTS OF INTEREST}

The authors declare no competing financial interests.

\section{FUNDING}

This study was supported by the grants The National Natural Science Foundation of China (81370269), and Shandong Taishan Scholarship (Ju Liu).

\section{REFERENCES}

1. White HD, Chew DP. Acute myocardial infarction. Lancet. 2008; 372:570-584. 
2. Spiel AO, Gilbert JC, Jilma B. von Willebrand factor in cardiovascular disease: focus on acute coronary syndromes. Circulation. 2008; 117:1449-1459.

3. Krumholz HM, Anderson JL, Bachelder BL, Fesmire FM, Fihn SD, Foody JM, Ho PM, Kosiborod MN, Masoudi FA, Nallamothu BK. ACC/AHA 2008 performance measures for adults with ST-elevation and non-ST-elevation myocardial infarction: a report of the American College of Cardiology/American Heart Association Task Force on Performance Measures (Writing Committee to develop performance measures for ST-elevation and non-STelevation myocardial infarction): developed in collaboration with the American Academy of Family Physicians and the American College of Emergency Physicians: endorsed by the American Association of Cardiovascular and Pulmonary Rehabilitation, Society for Cardiovascular Angiography and Interventions, and Society of Hospital Medicine. Circulation. 2008; 118:2596-2648.

4. Danese E, Montagnana M. An historical approach to the diagnostic biomarkers of acute coronary syndrome. Ann Transl Med. 2016; 4:194.

5. White HD, Thygesen K, Alpert JS, Jaffe AS. Clinical implications of the Third Universal Definition of Myocardial Infarction. Heart. 2014; 100:424-432.

6. Kanaji S, Fahs SA, Shi Q, Haberichter SL, Montgomery RR. Contribution of platelet vs. endothelial VWF to platelet adhesion and hemostasis. J Thromb Haemost. 2012; 10:1646-1652.

7. Yee A, Kretz CA. Von Willebrand factor: form for function. Semin Thromb Hemost. 2014; 40:17-27.

8. Wagner DD, Olmsted JB, Marder VJ. Immunolocalization of von Willebrand protein in Weibel-Palade bodies of human endothelial cells. J Cell Biol. 1982; 95:355-360.

9. Sporn LA, Chavin SI, Marder VJ, Wagner DD. Biosynthesis of von Willebrand protein by human megakaryocytes. J Clin Invest. 1985; 76:1102-1106.

10. Verhenne S, Denorme F, Libbrecht S, Vandenbulcke A, Pareyn I, Deckmyn H, Lambrecht A, Nieswandt B, Kleinschnitz C, Vanhoorelbeke K, De Meyer SF. Plateletderived VWF is not essential for normal thrombosis and hemostasis but fosters ischemic stroke injury in mice. Blood. 2015; 126:1715-1722.

11. Metcalf DJ, Nightingale TD, Zenner HL, Lui-Roberts WW, Cutler DF. Formation and function of Weibel-Palade bodies. J Cell Sci. 2008; 121:19-27.

12. Nightingale T, Cutler D. The secretion of von Willebrand factor from endothelial cells; an increasingly complicated story. J Thromb Haemost. 2013; 11:192-201.

13. Blann A. von Willebrand factor and the endothelium in vascular disease. Br J Biomed Sci. 1993; 50:125-134.

14. Boos CJ, Jaumdally RJ, MacFadyen RJ, Varma C, Lip GY. Circulating endothelial cells and von Willebrand factor as indices of endothelial damage/dysfunction in coronary artery disease: a comparison of central vs. peripheral levels and effects of coronary angioplasty. J Thromb Haemost. 2007; 5:630-632.

15. Goto S, Handa S. Coronary thrombosis. Effects of blood flow on the mechanism of thrombus formation. Jpn Heart J. 1998; 39:579-596.

16. Ikeda Y, Murata M, Goto S. Von Willebrand factordependent shear-induced platelet aggregation: basic mechanisms and clinical implications. Ann N Y Acad Sci. 1997; 811:325-336.

17. Oury C, Sticker E, Cornelissen H, De Vos R, Vermylen J, Hoylaerts MF. ATP augments von Willebrand factordependent shear-induced platelet aggregation through $\mathrm{Ca} 2+$-calmodulin and myosin light chain kinase activation. J Biol Chem. 2004; 279:26266-26273.

18. Montalescot G, Philippe F, Ankri A, Vicaut E, Bearez E, Poulard JE, Carrie D, Flammang D, Dutoit A, Carayon A, Jardel C, Chevrot M, Bastard JP, et al. Early increase of von Willebrand factor predicts adverse outcome in unstable coronary artery disease: beneficial effects of enoxaparin. French Investigators of the ESSENCE Trial. Circulation. 1998; 98:294-299.

19. Bertoluci MC, Ce GV, da Silva AM, Wainstein MV, Boff W, Punales M. Endothelial dysfunction as a predictor of cardiovascular disease in type 1 diabetes. World J Diabetes. 2015; 6:679-692.

20. van Loon JE, Kavousi M, Leebeek FW, Felix JF, Hofman A, Witteman JC, de Maat MP. von Willebrand factor plasma levels, genetic variations and coronary heart disease in an older population. J Thromb Haemost. 2012; 10:1262-1269.

21. Margulis T, David M, Maor N, Soff GA, Grenadier E, Palant A, Aghai E. The von Willebrand factor in myocardial infarction and unstable angina: a kinetic study. Thromb Haemost. 1986; 55:366-368.

22. Teunissen PF, Tijssen R, van Montfoort ML, Robbers LF, de Waard GA, van de Ven PM, Beek AM, Knaapen P, Meijers JC, van Royen N. Kinetics of coagulation in ST-elevation myocardial infarction following successful primary percutaneous coronary intervention. Thromb Res. 2016; 137:64-71.

23. Jia XQ, Dong CM, Qin J, Zhang L. Changes in coagulation and fibrinolysis in the patients with coronary heart disease in acute period and effect of drug intervention. [Article in Chinese]. Zhongguo Wei Zhong Bing Ji Jiu Yi Xue. 2012; 24:225-228.

24. Zhou Q, Li J, Luo XP, Shi HM, Chen H, Zhao BL, Zhu J, Ni HC, Shen W, Wang CP. Relationship between post-stenting coronary thrombolysis in myocardial infarction flow and plasma von Willebrand factor and ADAMTS-13 levels in patients with ST segment elevation myocardial infarction. [Article in Chinese]. Zhonghua Xin Xue Guan Bing Za Zhi. 2011; 39:212-216.

25. Matsukawa M, Kaikita K, Soejima K, Fuchigami S, Nakamura Y, Honda T, Tsujita K, Nagayoshi Y, Kojima S, Shimomura H, Sugiyama S, Fujimoto K, Yoshimura M, et al. Serial changes in von Willebrand factor-cleaving 
protease (ADAMTS13) and prognosis after acute myocardial infarction. Am J Cardiol. 2007; 100:758-763.

26. Xie Y, Zhou T, Shen W, Lu G, Yin T, Gong L. Soluble cell adhesion molecules in patients with acute coronary syndrome. Chin Med J (Engl). 2000; 113:286-288.

27. Sakai H, Goto S, Kim JY, Aoki N, Abe S, Ichikawa N, Yoshida M, Nagaoka Y, Handa S. Plasma concentration of von Willebrand factor in acute myocardial infarction. Thromb Haemost. 2000; 84:204-209.

28. Tousoulis D, Tentolouris C, Bosinakou E, Apostolopoulos T, Kyriakides M, Toutouzas P. Von Willebrand factor in patients evolving Q-wave versus non-Q-wave acute myocardial infarction. Int J Cardiol. 1996; 56:259-262.

29. Norris RM, Ockelford PA, Cross DB, Rivers JT, Smith JM, Takayama M, White HD. Reduced synthesis of tissue plasminogen activator by vascular endothelium during acute myocardial infarction. Aust N Z J Med. 1992; 22:261-264.

30. Andreotti F, Roncaglioni MC, Hackett DR, Khan MI, Regan T, Haider AW, Davies GJ, Kluft C, Maseri A. Early coronary reperfusion blunts the procoagulant response of plasminogen activator inhibitor-1 and von Willebrand factor in acute myocardial infarction. J Am Coll Cardiol. 1990; 1553-1560.

31. Lip GY, Lydakis C, Nuttall SL, Landray MJ, Watson RD, Blann AD. A pilot study of streptokinase-induced endothelial injury and platelet activation following acute myocardial infarction. J Intern Med. 2000; 248:316-318.

32. Regueiro A, Cuadrado-Godia E, Bueno-Beti C, DiazRicart M, Oliveras A, Novella S, Gene GG, Jung C, Subirana I, Ortiz-Perez JT, Roque M, Freixa X, Nunez J, et al. Mobilization of endothelial progenitor cells in acute cardiovascular events in the PROCELL study: time-course after acute myocardial infarction and stroke. J Mol Cell Cardiol. 2015; 80:146-155.

33. Sixma JJ, Sakariassen KS, Beeser-Visser NH, OttenhofRovers M, Bolhuis PA. Adhesion of platelets to human artery subendothelium: effect of factor VIII-von Willebrand factor of various multimeric composition. Blood. 1984; 63:128-139.

34. Fujikawa K, Suzuki H, McMullen B, Chung D. Purification of human von Willebrand factor-cleaving protease and its identification as a new member of the metalloproteinase family. Blood. 2001; 98:1662-1666.

35. Soejima K, Mimura N, Hirashima M, Maeda $H$, Hamamoto T, Nakagaki T, Nozaki C. A novel human metalloprotease synthesized in the liver and secreted into the blood: possibly, the von Willebrand factor-cleaving protease? J Biochem. 2001; 130:475-480.

36. Gerritsen HE, Robles R, Lammle B, Furlan M. Partial amino acid sequence of purified von Willebrand factorcleaving protease. Blood. 2001; 98:1654-1661.

37. Crawley JT, Lane DA, Woodward M, Rumley A, Lowe GD. Evidence that high von Willebrand factor and low ADAMTS-13 levels independently increase the risk of a non-fatal heart attack. J Thromb Haemost. 2008; 6:583-588.

38. De Caterina R, Madonna R. Von Willebrand factor, ADAMTS13, and coronary microvascular obstruction: beautiful hypotheses, ugly facts. Cardiovasc Res. 2016; 111:169-171.

39. Zezos P, Papaioannou G, Nikolaidis N, Vasiliadis T, Giouleme O, Evgenidis N. Elevated plasma von Willebrand factor levels in patients with active ulcerative colitis reflect endothelial perturbation due to systemic inflammation. World J Gastroenterol. 2005; 11:7639-7645.

40. Pinsky DJ, Naka Y, Liao $\mathrm{H}, \mathrm{Oz}$ MC, Wagner DD, Mayadas TN, Johnson RC, Hynes RO, Heath M, Lawson CA, Stern DM. Hypoxia-induced exocytosis of endothelial cell Weibel-Palade bodies. A mechanism for rapid neutrophil recruitment after cardiac preservation. J Clin Invest. 1996; 97:493-500.

41. Ruggeri ZM, Ware J. von Willebrand factor. Faseb j. 1993; 7:308-316.

42. Miura S, Li CQ, Cao Z, Wang H, Wardell MR, Sadler JE. Interaction of von Willebrand factor domain A1 with platelet glycoprotein Ibalpha-(1-289). Slow intrinsic binding kinetics mediate rapid platelet adhesion. J Biol Chem. 2000; 275:7539-7546.

43. Santoro SA. Adsorption of von Willebrand factor/factor VIII by the genetically distinct interstitial collagens. Thromb Res. 1981; 21:689-691.

44. Penttila I, Penttila K, Rantanen T. Laboratory diagnosis of patients with acute chest pain. Clin Chem Lab Med. 2000; 38:187-197.

45. Ohman EM, Casey C, Bengtson JR, Pryor D, Tormey W, Horgan JH. Early detection of acute myocardial infarction: additional diagnostic information from serum concentrations of myoglobin in patients without ST elevation. Br Heart J. 1990; 63:335-338.

46. Sorensen NS. Creatine phosphokinase in the diagnosis of myocardial infarction. Acta Med Scand. 1963; 174:725-734.

47. Gamble JH, Carlton EW, Orr WP, Greaves K. Highsensitivity cardiac troponins: no more 'negatives'. Expert Rev Cardiovasc Ther. 2013; 11:1129-1139.

48. Montalescot G, Collet JP, Lison L, Choussat R, Ankri A, Vicaut E, Perlemuter K, Philippe F, Drobinski G, Thomas D. Effects of various anticoagulant treatments on von Willebrand factor release in unstable angina. J Am Coll Cardiol. 2000; 36:110-114.

49. Collet JP, Montalescot G, Vicaut E, Ankri A, Walylo F, Lesty C, Choussat R, Beygui F, Borentain M, Vignolles N, Thomas D. Acute release of plasminogen activator inhibitor-1 in ST-segment elevation myocardial infarction predicts mortality. Circulation. 2003; 108:391-394.

50. Ray KK, Morrow DA, Gibson CM, Murphy S, Antman EM, Braunwald E. Predictors of the rise in vWF after ST elevation myocardial infarction: implications for treatment strategies and clinical outcome: An ENTIRE-TIMI 23 substudy. Eur Heart J. 2005; 26:440-446. 